\title{
Effect of MoS2 as a Buffer Layer on CdTe Photovoltaic Cell Through Numerical Simulation
}

\author{
Nitesh Kumar Singh, Anshul Agarwal and Tirupathiraju Kanumuri \\ Department of Electrical \& Electronics Engineering, National Institute of Technology Delhi, New Delhi, India \\ Corresponding Author: anshul@nitdelhi.ac.in
}

\begin{abstract}
A thin film based Cadmium Telluride photovoltaic cell is becoming highly competitive in the electric power industry. The major problem with the CdTe photovoltaic cell is the large barrier height behind the rear contact surface that prevents the solar cell to reach notional efficiency of 32\%. A buffer layer is added to get a better result in terms of efficiency by reducing the valence barrier height at the rear contact surface of the CdTe photovoltaic cell. This manuscript presents the numerical simulation and optimization of ITO/TiO $2 / \mathrm{CdS} / \mathrm{CdTe} / \mathrm{MoS} 2 / \mathrm{Au}$ original photovoltaic cell structure using SCAPS 1D software. Furthermore, the effect of CdTe thickness, defect density, and acceptor density of MoS2 layer is discussed. Simulation results show that with the optimization of layer and parameters of the photovoltaic cell, efficacy of the photovoltaic cell is quite improved. With optimized solar cell, efficiency is improved to $26.49 \%$, $\mathrm{Voc}=1.141 \mathrm{~V}, \mathrm{Jsc}=27.690 \mathrm{~mA} / \mathrm{cm} 2, \mathrm{FF}=83.80 \%$ as compared to basic CdTe model which has an efficiency of $21.69 \%$.
\end{abstract}

Keywords : CdTe; Thickness; MoS2; Thin layer

\section{INTRODUCTION}

The world power consumption is increasing enormously today, owing to population growth. In today's scenario, the primary source of energy is fossil fuels (Nadeem Khan et al., 2020). The combustion of fossil fuels generates a large quantity of $\mathrm{CO} 2$ gas. So, this is not a feasible energy source for the future generation. Therefore, the best solution is to move towards green renewable energy sources. In green energy, amplest amount of solar energy is present in our earth's atmosphere. Utilization of this solar energy using solar cell is the best alternative source as compared to fossil fuels (Vinod et al., 2019). Silicon-based fabricated solar cells are efficient solar cells, but they involve very costly fabricating techniques. So, in search of inexpensive solar cell technology, many researchers have focused on 3rd generation thin layer photovoltaic cell technology as a possible solution against the Si photovoltaic cell. A large number of researchers have focused on perovskite and polymer photovoltaic cells (Lee et al., 2019). However, perovskite and polymer photovoltaic cells have drawback of instability, which restricts their long-life use. Thus, environmentally stable, inorganic thin layer solar multijunction cells may be the right substitute to perovskite \& polymer-based photovoltaic cells (Yi et al., 2019).

The primary materials which are used for the absolute inorganic thin layer multi junction photovoltaic cells include group III-V fusion \& alloys, chalcogenide solar cell, CIGS solar cell, cadmium sulphide (CdS), cadmium selenide (CdSe) as well as cadmium telluride (CdTe) solar cell (Liu et al., 2020). CdTe, A-Si cell, and CIGS photovoltaic cells are one of the most fortunate heterojunction thin layer photovoltaic cells present in the market. It has been reported that technology used in CdTe is about 30\% cheaper than CIGS and about $40 \%$ less than the technology for silicon solar cells (Lee et al., 2016). Thus, the maximum efficiency/cost ratio could be obtained with thin layer heterojunction power cells based on Cadmium Telluride (Wu et al., 2004). Till now CdTe solar cell has achieved an efficiency of only $22.1 \%$ practically (Green et al., 2020) even though the efficiency of close to $32 \%$ is possible theoretically (Agostinelli et al., 2003). This is primarily due to the absorption losses of short $\mathrm{CdS}$ wavelength and an interlinking 
film at the rear contact of the CdTe photovoltaic cell. Introduction of a Buffer film at rear touch of CdTe photovoltaic cell could improve the hole transport movement of the solar cell and could decrease the Schottky barrier at rear contact also.

In the photovoltaic industry, p-type CdTe material has attained much hype in the last two decades (Tinedert et al., 2020) with a direct bandgap of $1.5 \mathrm{eV}$ which fits the solar spectrum very well. The light-capturing capacity of CdTe is very high (10-5 cm-1) which enables the solar cell to capture light more than $90 \%$ above the bandgap of CdTe material with a thickness of 1 to $2 \mu \mathrm{m}$. Generally, CdTe material is fabricated with n-type CdS material. This semiconductor material is used as a window layer in the photovoltaic cell with a direct bandgap of $2.4 \mathrm{eV}$ which suitably fits with CdTe heterojunction structure. The cell output depends heavily on the energy barrier of the photovoltaic cell's absorbent layer and rear contact. The energy barrier can be reduced by using a buffer layer of low resistance rear contact with high work function (WF). In the past, different buffer layer was used as hole transport layer (HTL) such as NiO, MoOx, V2O5, etc (Kuddus et al., 2019, Lin et al., 2012, \& Ahmmed et al., 2020) in practical CdTe solar cell to boost the efficiency of the photovoltaic cell. In transition metal oxide (TMO) family MoS2 (Molybdenum Disulphide) is one of the encouraging HTL layers ample to its favourable WF of $4.0 \mathrm{eV}$ with a range of bandgap of $1.8 \mathrm{eV}$ to $2.8 \mathrm{eV}$. MoS2 plays a very important role in reducing photovoltaic cell back contact losses and in enhancing cell efficiency. The front of the solar cell uses an optically transparent material to move the exciton to an outer load. As the front layer of the photovoltaic cell CdTe, Indium tin oxide (ITO) or Fluorine tin oxide (FTO) are mainly used. TiO2 is been used as a high resistive thin film between the CdS layer and ITO.

\section{NOVELTY OF THE RESEARCH}

$>$ The use of th3as a buffer layer enhances the electrical properties of the CdTe photovoltaic cell.

$>$ Optimization of CdTe with MoS2 layer photovoltaic cells enhances the efficiency of the photovoltaic cell by 4.8 percent than the basic CdTe structure solar cell.

In this research paper, a study of novel heterojunction solar cell ITO/TiO2/CdS/CdTe/MoS2/Au with and without MoS2 as a buffer layer design was developed with the help of numerical simulation program SCAPS 1D software. To analyze the design of the solar cell different configuration parameters are varied such as thickness, defect density, acceptor concentration, the temperature of the photovoltaic cell. The aim of this research is to enhance solar cell efficiency by introducing a rear contact buffer layer so that the Schottky barrier of the cell could be reduced and the flow of holes could easily happen towards metal contact. The introduction of MoS2 (buffer layer) reduces carrier losses and results in an increase in the efficiency/cost ratio of the cell by optimizing its parameters.

\section{MODELLING AND NUMERICAL SIMULATION PARAMETERS}

To solve the semiconductor material characteristics equation, different solar cell simulation software's are present in the market such as Silvaco, Amps 1D, Cosmol, SCAPS 1D, etc. Scaps 1D is one of the popular software to other software due to its capability to design max. 7 layers of thin-film photovoltaic cell \& measured different uncommon measurements (Heriche et al., 2017). In this manuscript, SCAPS 1D was used to model and simulate $\mathrm{ITO} / \mathrm{TiO} 2 / \mathrm{CdS} / \mathrm{CdTe} / \mathrm{MoS} 2 / \mathrm{Au}$ heterojunction solar cells. This simulation program works on the fundamentals of the Poisson \& the continuity equation of electron and holes. The following equations are used to compute the numerical measurements of the photovoltaic cell. equations are used to compute the numerical measurements of the photovoltaic cell.

$$
\frac{d^{2} \psi}{d y^{2}}+\frac{q}{\varepsilon}\left[h(y)-e(y)+P_{d}-P_{a}+\rho_{h}-\rho_{e}\right]=0
$$




$$
\begin{aligned}
& \frac{1}{q} \frac{d J_{h}}{d y}=G-R(y) \\
& \frac{1}{q} \frac{d J_{e}}{d y}=-G+R(y)
\end{aligned}
$$

Here, $\Psi$ represents electrostatic potential, q describes electron charge, e $\& \mathrm{~h}$ are the electron and hole density respectively, $\mathrm{Pd} \& \mathrm{~Pa}$ are donor concentration and acceptor concentration respectively, $\varepsilon$ represents dielectric constant, G \& R represents photon generation rate and total recombination rate respectively, Je \& Jh describes electron current density and hole current density respectively, oh \& @e represents hole and electron distribution.

Carrier transportation equation of electron and hole are given by

$$
\begin{aligned}
& J_{h}=-\frac{\mu_{h} h}{q} \frac{d E_{f h}}{d y} \\
& J_{e}=-\frac{\mu_{e} e}{q} \frac{d E_{f e}}{d y}
\end{aligned}
$$

$\mu \mathrm{e} \& \mu \mathrm{h}$ are mobility of electron and hole respectively, Efe and Efh are fermi level of electron \& hole respectively.

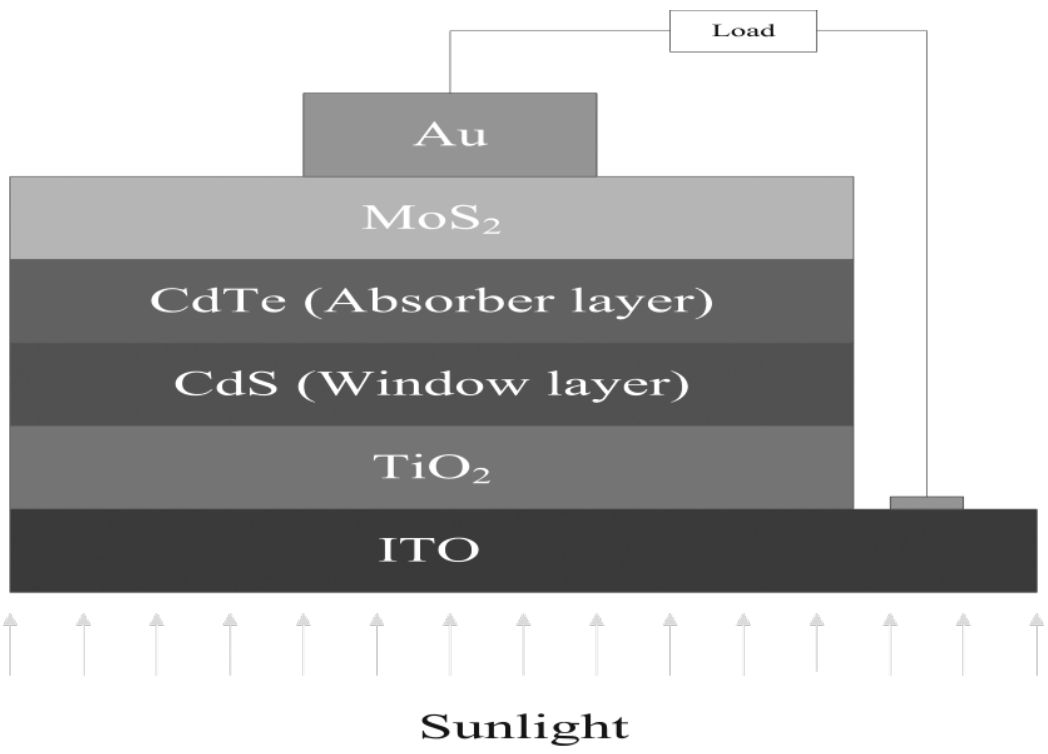

Figure 1. Thin Film CdTe Solar Cell Structure 
Table 1. Boundary Condition of CdTe solar cell

\begin{tabular}{|c|c|c|c|c|c|}
\hline & CdTe & MoS2 & CdS & TiO2 & FTO \\
\hline Thickness $(\mu \mathrm{m})$ & 3 & 0.650 & 0.1 & 0.1 & 0.4 \\
\hline Eg $(e V)$ & 1.5 & 1.8 & 2.42 & 3.2 & 3.5 \\
\hline$\varepsilon r(e V)$ & 9.4 & 11.9 & 10 & 10 & 9 \\
\hline $\mathrm{Nc}(\mathrm{cm}-3)$ & $8 \times 10^{17}$ & $1 \times 1019$ & $2.2 \times 10^{18}$ & $2 \times 10^{17}$ & $2.2 \times 10^{18}$ \\
\hline Nv (cm-3) & $1.8 \times 10^{19}$ & $9 \times 1020$ & $1.8 \times 10^{19}$ & $6 \times 10^{17}$ & $1.8 \times 10^{19}$ \\
\hline$\mu \mathrm{e}(\mathrm{cm} 2 \mathrm{v}-1 \mathrm{~s}-1)$ & 320 & 200 & 100 & 100 & 100 \\
\hline$\mu \mathrm{h}(\mathrm{cm} 2 \mathrm{v}-1 \mathrm{~s}-1)$ & 60 & 67 & 25 & 250 & 25 \\
\hline Pd (cm-3) & - & - & $1 \times 10^{18}$ & $1 \times 10^{17}$ & $2 \times 10^{19}$ \\
\hline $\mathrm{Pa}(\mathrm{cm}-3)$ & $2 \times 10^{14}$ & $1 \times 1019$ & - & - & - \\
\hline$\chi$ & 4.28 & 4 & 4.3 & 4.2 & 4.5 \\
\hline $\mathrm{Nt}(1 / \mathrm{cm} 3)$ & $2.50 \times 10^{15}$ & - & $2.50 \times 10^{15}$ & - & - \\
\hline
\end{tabular}

Table 2. Simulated Result of CdTe photovoltaic cell with and without MoS2

\begin{tabular}{|l|c|c|c|c|}
\hline & $\mathbf{V}_{\text {oc }}(\mathbf{V})$ & $\mathbf{J}_{\text {sc }}(\mathbf{m A} / \mathbf{c m} 2)$ & FF (\%) & Efficiency (\%) \\
\hline Without MoS2 & 0.894 & 28.498 & 85.12 & 21.69 \\
\hline With MoS2 & 0.944 & 28.518 & 84.18 & 22.66 \\
\hline
\end{tabular}

Fizhin layer CdTe photovoltaic cell structure with MoS2 as a buffer layer in it. Light enters from the ITO layer which is a good receiver as well as a good absorber of light, TiO2 subsequent layer acts as a high restive layer between CdS and ITO. CdS layer forms a window layer between CdTe and TiO2. In this solar cell, CdTe acts as the main absorbent layer which absorbs most of the sunlight, and MoS2 acts as a HTL to the photovoltaic cell. Gold is the back-contact material. Table 1 shows the boundary condition of semiconductor materials used in modelling the device. The parameters been taken from different literature (Tinedert et al., 2020, Dadashbeik et al., 2020, Lin et al., 2019, \& Kirner et al., 2015). Modelling of the solar cell is performed under AM 1.5 light range with $1000 \mathrm{~W} / \mathrm{m} 2$ light intensity. The temperature used in this paper is $300 \mathrm{~K}$ to model the CdTe solar cell. 


\section{RESULTS AND DISCUSSION}

Primarily modelling of Cadmium Telluride photovoltaic cell was simulated with the parameters mentioned in Table 1. The performance of photovoltaic cell with and without MoS2 material is illustrated in Table 2. The efficacy of the photovoltaic cell is increased by 0.97 percent compared to without the MoS2 layer.

\section{Influence of thickness on CdTe solar cell}

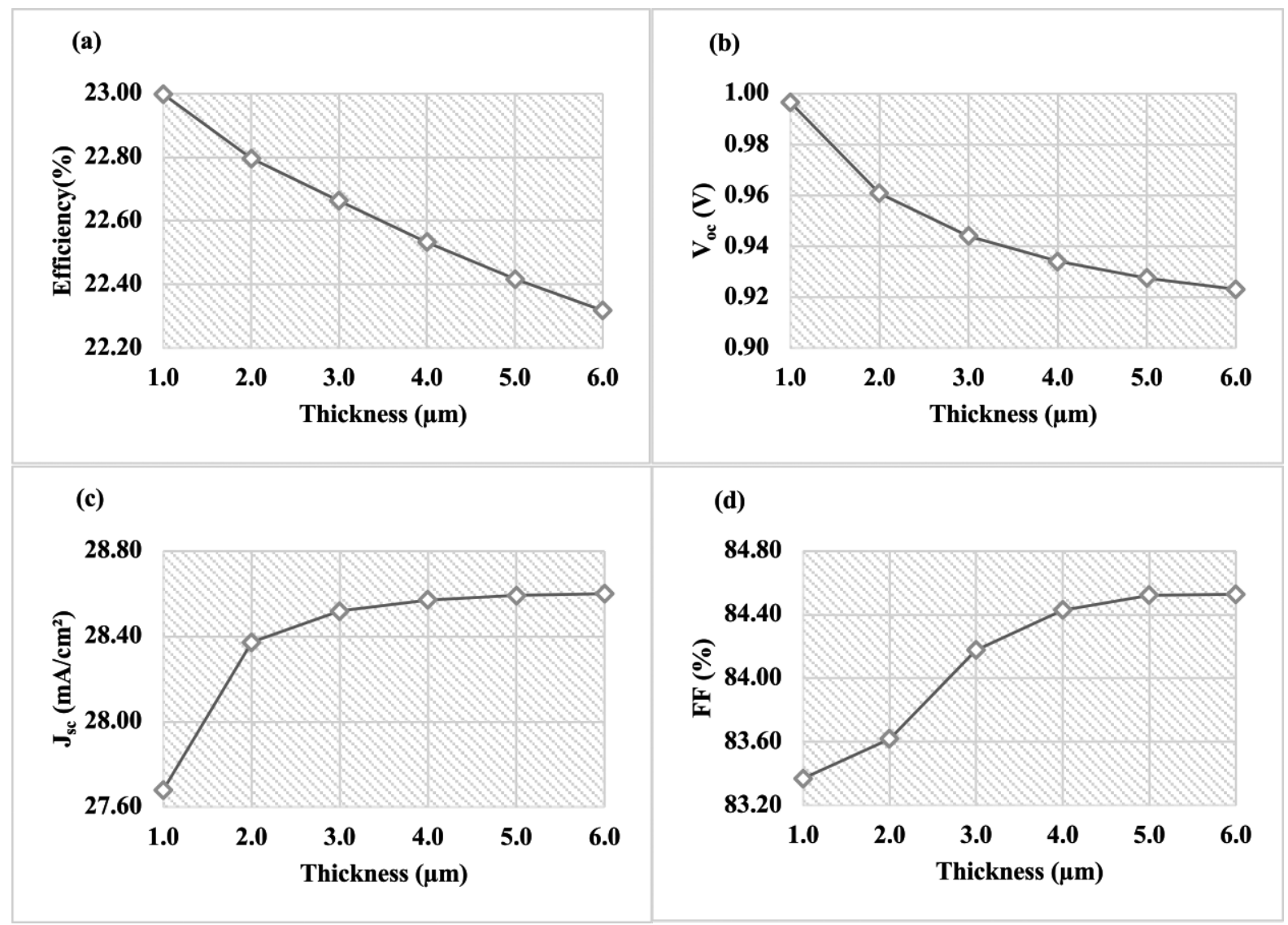

Figure 2. Influence of CdTe thickness variation

A simulation was performed on Cadmium Telluride photovoltaic cell by varying the thickness of the CdTe film from $1 \mu \mathrm{m}$ to $6 \mu \mathrm{m}$ and keeping all other specification as default in Table 1. Figure 2 shows the influence of thickness variation on CdTe photovoltaic cells. With the increase of thickness of CdTe film efficiency (Eta) of the CdTe photovoltaic cell decreases from $22.99 \%$ to $22.31 \%$ as depicted in Fig. 2(a). $\mathrm{V}_{\text {oc }}$ decline from $0.99 \mathrm{~V}$ to $0.92 \mathrm{~V}$ shown in Fig. 2(b). The downtick in the Eta and $\mathrm{V}_{\mathrm{oc}}$ is due to the increase in the recombination of electron \& hole pairs in this layer. As the thickness of the absorbance film is been increased beyond carrier diffusion length, the recombination of excitons also increases (Abdelaziz et al., 2020). The other reason for the decrease in Eta is the presence of the MoS2 layer which decreases the valence barrier height also. Although current density and FF are depicted in Fig. 2(c,d) rise from $27.68 \mathrm{~mA} / \mathrm{cm} 2$ to $28.60 \mathrm{~mA} / \mathrm{cm} 2$ and $83.37 \%$ to $84.52 \%$ respectively. The elevation of $\mathrm{J}_{\mathrm{sc}}$ is mainly anticipated to the absorption of more photons in the CdTe layer with a change of thickness. FF increases due to a decrease in the series resistance of the photovoltaic cell as thickness is varied. Therefore, a maximum Eta of $22.99 \%$ was achieved at $1 \mu \mathrm{m}$ thickness. 
Influence of Defect Density on CdTe solar cell
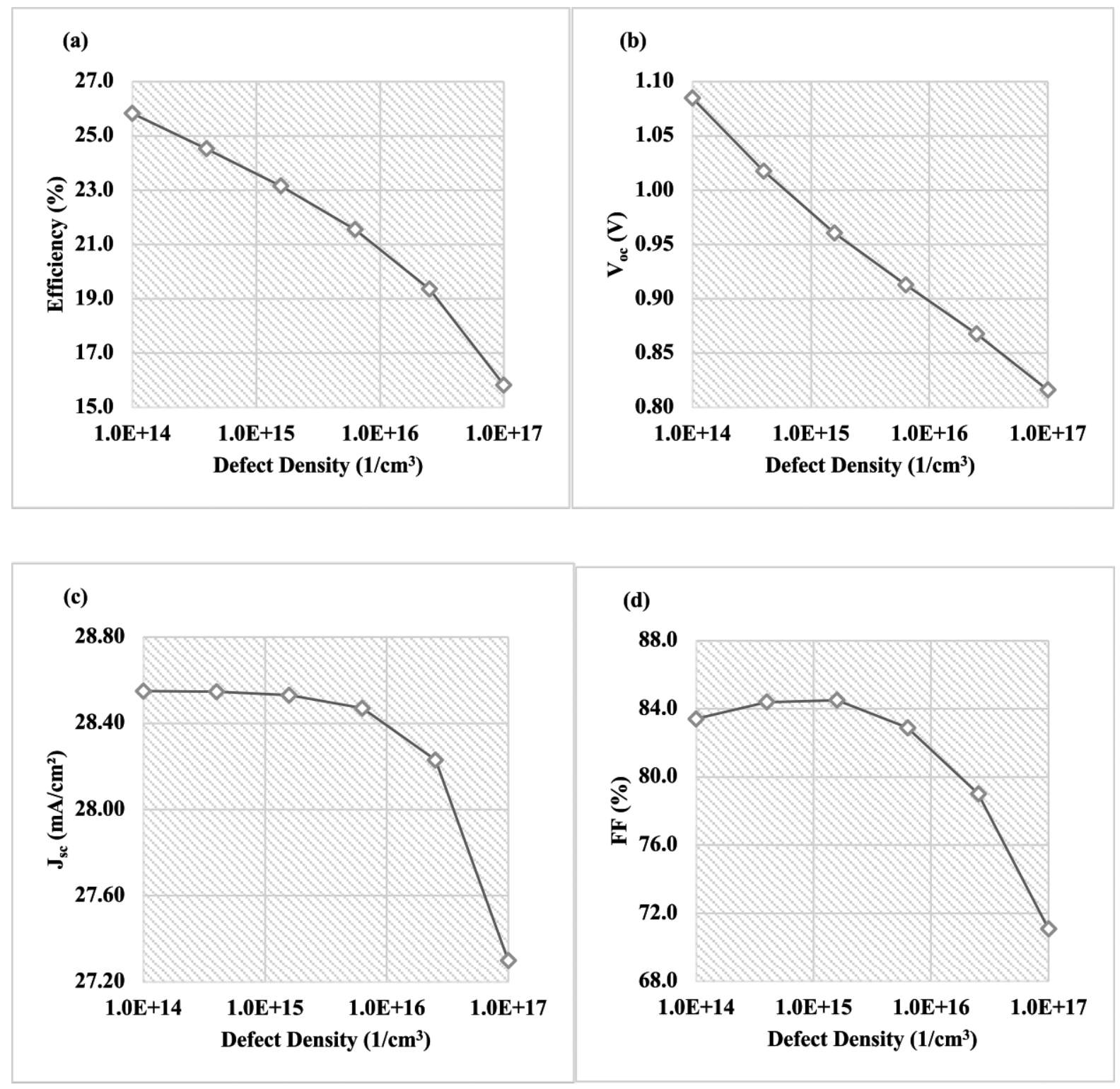

Figure 3. Response of Defect Density on CdTe photovoltaic cell

Analysis of defect concentration on CdTe solar cell is a very pivotal method for the variation of efficiency of the photovoltaic cell. Since a change in defect density might cause degradation of the CdTe layer which absorbs most of the sunlight and also increases the recombination of a carrier as well as a decrease in life expectancy of the photovoltaic cell. So, by maintaining boundary condition as the same given in Table 1, defect density is varied from $1 \times 10^{14}\left(1 / \mathrm{cm}^{3}\right)$ to $1 \times 10^{17}\left(1 / \mathrm{cm}^{3}\right)$ to examine the response. In Fig. 3(a) Eta of the photovoltaic cell decreases from $25.83 \%$ to $15.83 \%$ as defect density is varied. While other parameters $\mathrm{V}_{\mathrm{oc}}$, $\mathrm{J}_{\mathrm{sc}}$, FF declines to $0.81 \mathrm{~V}, 27.29$ $\mathrm{mA} / \mathrm{cm}^{2}, 71.07 \%$ correspondingly as outlined in Fig. 3(b-d). The decline in all solar cell's electrical parameters is predominantly due to the energy trap located on the interface of the $\mathrm{CdTe} / \mathrm{CdS}$ layer and the $\mathrm{CdTe} / \mathrm{MoS}_{2}$ layer. 
These traps states cause more amalgamation of electron-hole pairs as compared to the generation of photons. The above figures show that motion of electron will be obstructed with increase in defect density. So, to increase in efficiency of CdTe photovoltaic cell, defect density should be maintained at a low value i.e. $2 \times 10^{14} \mathrm{~cm}^{-3}$.

\section{Influence of Acceptor Density on MoS2 Layer}
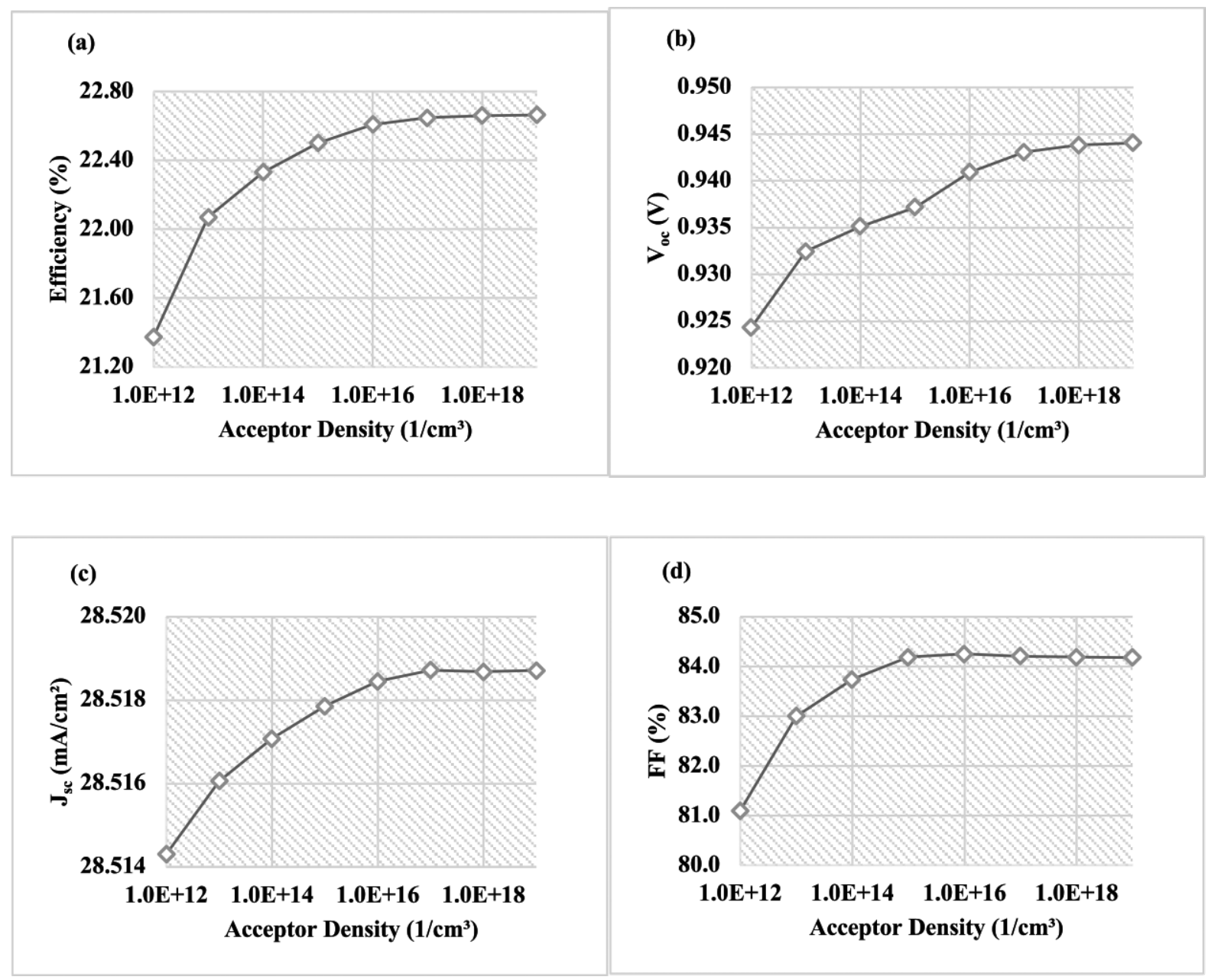

Figure 4. Variation of acceptor density on MoS2 layer

This section shows the effect of variation of acceptor concentration from $1 \times 10^{12}\left(1 / \mathrm{cm}^{3}\right)$ to $1 \times 10^{19}\left(1 / \mathrm{cm}^{3}\right)$ on the MoS2 layer as depicted in figure 4. When the acceptor concentration of MoS2 has increased all electrical parameters of the CdTe solar cell are also increased. The reason for increment in all values is the increase in hole concentration of $\mathrm{MoS}_{2}$ layer which causes the valence barrier height to decrease at rear contact of the photovoltaic cell. The efficacy of the cell increases from $21.37 \%$ to $22.66 \%$ as shown in Fig. 4(a). While $\mathrm{J}_{\mathrm{sc}}, \mathrm{V}_{\mathrm{oc}}$, FF increase to $28.51 \mathrm{~mA} / \mathrm{cm} 2,0.94 \mathrm{~V}, 84.17 \%$ correspondingly as outlined in Fig. 4(b-d). So, by analyzing the graph acceptor concentration of $1 \times 10^{19}\left(1 / \mathrm{cm}^{3}\right)$ should be maintained to achieve an efficiency of $22.66 \%$. 


\section{Optimized Design}

For achieving an optimized CdTe solar cell, simulation is been performed after investigation of optimized values of the CdTe thickness layer, defect density of CdTe film, and effect of acceptor concentration of $\mathrm{MoS}_{2}$ layer. The optimized electrical value of the CdTe structure result is outlined in Table 3. Figure 5 depicts the optimized $\mathrm{CdTe} / \mathrm{MoS}_{2} \mathrm{~J}-\mathrm{V}$ characteristic graph. This optimized result is far better than CdTe without MoS2 structure. The efficiency increases by about 4.8 percent with optimized structure compared to basic CdTe structure which has no $\mathrm{MoS}_{2}$ layer in it.

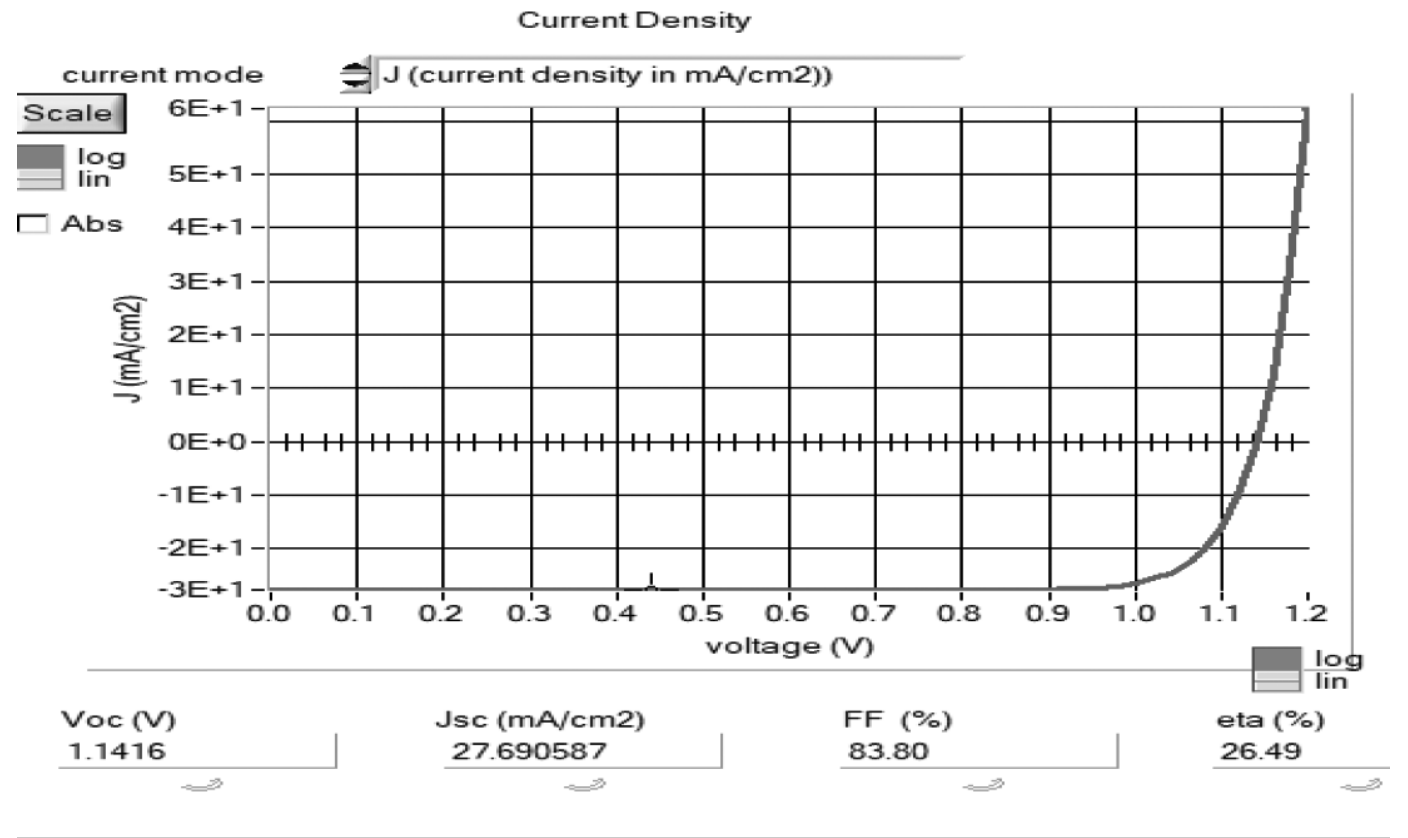

Figure 5. J-V characteristic graph of optimized CdTe solar cell

Table 3. Optimized design of CdTe/MoS2photovoltaic cell

\begin{tabular}{|c|c|c|c|c|}
\hline & Voc $(\mathbf{V})$ & Jsc $(\mathbf{m A} / \mathbf{c m} 2)$ & FF (\%) & Eta (\%) \\
\hline $\begin{array}{c}\text { Optimized } \\
\text { CdTe / MoS2 } \\
\text { Structure }\end{array}$ & 1.141 & 27.690 & 83.80 & 26.49 \\
\hline
\end{tabular}




\section{Influence of Temperature on optimized $\mathrm{CdTe} / \mathrm{MoS}_{2}$ solar cell}

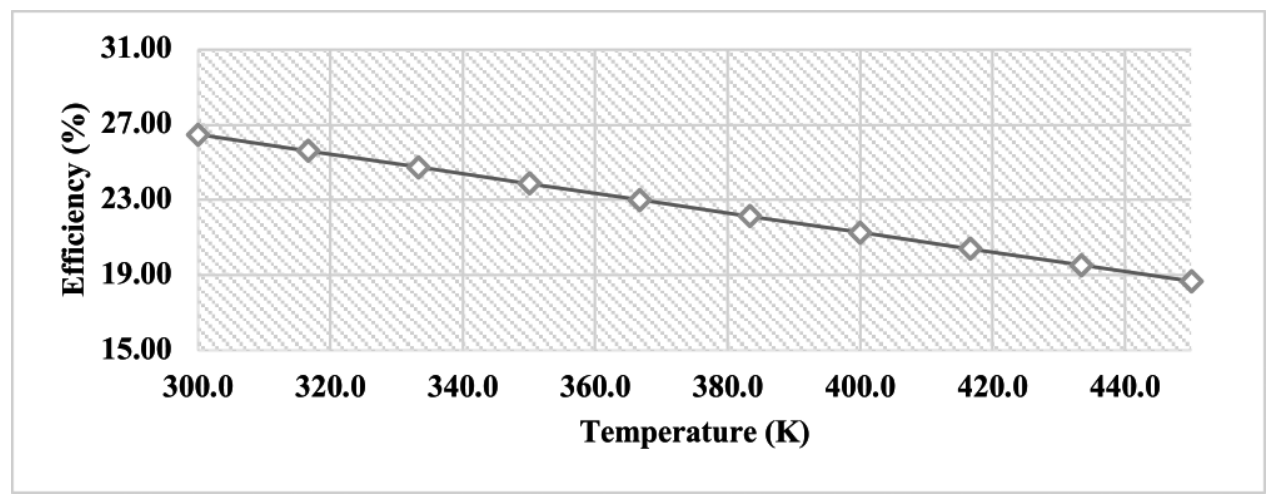

Figure 6. Influence of temperature on optimized CdTe photovoltaic cell

Figure 6 shows analysis of temperature against the efficiency of the photovoltaic cell when varied from $300 \mathrm{~K}$ to $450 \mathrm{~K}$. Above results show that temperature has a decreasing linear nature to the efficiency of the photovoltaic cell. Eta decreases from $26.49 \%$ to $18.68 \%$ at $450 \mathrm{~K}$. As the temperature of the solar cell is increased velocity of charged particles also rises. But, the effect of the recombination of electron and hole pairs also start to rise which dominates than the generation of photons. As a consequence, there is a reduction in the number of free carriers. Hence efficacy of the photovoltaic cell gradually decreases linearly.

\section{CONCLUSION}

In this manuscript, a study of numerical simulation of CdTe photovoltaic cells was performed with the aid of SCAPS 1D software. A buffer layer of MoS2 was introduced at the rear contact of the CdTe photovoltaic cell. In comparison with a CdTe structure with no MoS2 layer, solar cell buffer film efficiency is up by 0.97 percent. The buffer layer reduces the work function of the back contact material. Furthermore, an influence of CdTe film thickness variation, the influence of CdTe defect density, and the influence of acceptor concentration on the MoS2 layer was examined. After scrutinizing the optimized values of thickness, defect concentration, \& acceptor concentration, efficiency of the solar cell increases by $4.8 \%$ compared to the basic CdTe structure which has no MoS2 layer in it. With optimum parameters efficiency becomes $26.49 \%$, open circuit voltage $=1.141 \mathrm{~V}$, current density $=27.690$ $\mathrm{mA} / \mathrm{cm} 2 \&$ fill factor $=83.80 \%$. The impact of the temperature is also investigated, showing that the solar cell's output at $450 \mathrm{~K}$ is $18.68 \%$, which shows the best execution at this temperature. This examination could therefore provide the necessary measures for producing the low price of the photovoltaic cells based on Cadmium Telluride with MoS2 layer.

\section{REFERENCES}

Abdelaziz, S., Zekry, A., Shaker, A., \& Abouelatta, M., 2020. Investigating the performance of formamidinium tin-based perovskite solar cell by SCAPS device simulation. Optical Materials 101: 109738.

Agostinelli, G., Bätzner, D.L., \& Burgelman, M., 2003. A theoretical model for the front region of cadmium telluride solar cells. Thin Solid Films 431-432: 407-413.

Ahmmed, S., Aktar, A., Rahman, F., \& Hossain, J., 2020. A Numerical Simulation of High Efficiency CdS/CdTe Based Solar Cell Using NiO HTL and ZnO TCO. Optik 223: 165625.

Dadashbeik, M., Fathi, D., and Eskandari, M., 2020. Design and Simulation of Perovskite Solar Cells Based on Graphene and TiO2/Graphene Nanocomposite as Electron Transport Layer. Solar Energy 207: 917-924. 
Green, M. A., Dunlop, E. D., Hohl-Ebinger, J., Yoshita, M., Kopidakis, N., \& Ho-Baillie, A. W. Y., 2020. Solar Cell Efficiency Tables (Version 55). Progress in Photovoltaics Research and Applications. 28(1): 3-15.

Heriche, H., Rouabah, Z., \& Bouarissa, N., 2017. New ultra thin CIGS structure solar cells using SCAPS simulation program. International Journal of Hydrogen Energy 42: 9524-9532.

Kirner, S., Hartig, M., Mazzarella, L., Korte, L., Frijnts, T., Ring, S., Stannowski, B., Rech, B., \& Schlatmann, R., 2015. The Influence of ITO Dopant Density on J-V Characteristics of Silicon Heterojunction Solar Cells: Experiments and Simulations.

Energy Procedia. 77(i): 725-732.

Kuddus, A., Rahman, F., Ahmmed, S., Hossain, J., \& Bakar, A., 2019. Superlattices and Microstructures Role of Facile Synthesized V2O5 as Hole Transport Layer for CdS / CdTe Heterojunction Solar Cell: Validation of Simulation Using Experimental Data, Superlattices Microstructures 132: 106168.

Lee, C., Lee, S., Kim, G. U., Lee, W., \& Kim, B. J., 2019. Recent Advances, Design Guidelines, and Prospects of All-Polymer Solar Cells. Chemical Reviews. 119(13): 8028-8086.

Lee, T. D., \& Ebong, A. U., 2016. A Review of Thin Film Solar Cell Technologies and Challenges. Renewable and Sustainable Energy Reviews 70: 1286-1297.

Lin, H., Xia, W., Wu, H. N., Gao, Y., \& Tang, C. W., 2012. Solar Energy Materials \& Solar Cells MoOx Back Contact for CdS / CdTe Thin Film Solar Cells: Preparation , Device Characteristics , and Stability. Solar Energy Materials and Solar Cells 99: 349-355.

Lin, J., Xu, J., \& Yang, Y., 2019. Numerical analysis of the effect of MoS2 interface layers on Copper-zinc-tin-sulphur thin film solar cells. Optik 201: 163496.

Liu, F., Zeng, Q., Li, J., Hao, X., Ho-baillie, A., Tang, J., \& Green, M. A., 2020. Emerging Inorganic Compound Thin Film Photovoltaic Materials:Progress, Challenges and Strategies. Materials Today, (Article in Press) 1-23.

Nadeem Khan, M. F., Malik, T. N., \& Sajjad, I. A. 2020. A Novel Probabilistic Generation Model for Grid Connected PV Based Distributed Generation. Journal of Engineering and Research. 8(1): 231-247.

Tinedert, I.E., Pezzimenti, F., Megherbi, M.L., \& Saadoune, A., 2020. Design and simulation of a high efficiency CdS/CdTe solar cell. Optik 208: 164112.

Tinedert, I.E., Saadoune, A., Bouchama, I., \& Saeed, M.A., 2020. Numerical modelling and optimization of $\mathrm{CdS} / \mathrm{CdTe}$ solar cell with incorporation of Cu2O HT-EBL layer. Optical Materials 106: 109970.

Vinod, A., \& Sinha, A. K., 2019. Estimation of Parameters for One Diode Solar PV Cell Using Grey Wolf Optimizer to Obtain Exact V-I Characteristics. Journal of Engineering Research. 7(1): 1-19.

Wu, X., 2004. High-Efficiency Polycrystalline CdTe Thin-Film Solar Cells. Solar Energy. 77(6): 803-814.

Yi, Z., Ladi, N. H., Shai, X., Li, H., Shen, Y., \& Wang, M., 2019. Will Organic-Inorganic Hybrid Halide Lead Perovskites Be Eliminated from Optoelectronic Applications?. Nanoscale Advances. 1(4): 1276-1289. 